\title{
SIMULATING DRAINAGE FROM A FLOODED SINKHOLE
}

\section{SIMULACIJA ODTOKA IZ POPLAVLJENEGA POŽIRALNIKA}

\author{
Malcolm S. FIELD ${ }^{1}$
}

\begin{abstract}
UDC 556.34:519.216

Malcolm S. Field: Simulating Drainage from a Flooded Sinkhole

Understanding sinkhole-drainage capacity and functioning is critical to realizing the effects that may be created when directing stormwater drainage into sinkholes. In this paper, the basics of sinkhole drainage are reviewed in terms of point vortex flow created by drainage down a sinkhole swallet. Then, several different, relatively simple sinkhole shapes are presented and mathematical models developed to simulate drainage from inflowing water. The models emphasize the significance of drainage rate as a function of sinkhole shape and sinkhole wetted cross-sectional area relative to changes in water level and time. Model simulations provide insights into the sensitivity of sinkholes to inflow rates and water-level changes with time. Major findings include insights into the rapidity by which inflows may increase the water level in a sinkhole and the significance of sinkhole shape and cross-sectional area as it relates to sinkhole drainage rate. The numerical solution is completely general so it allows for varying inflow rates in any manner desired. Application of the model to real sinkholes should assist in the management of sinkhole-flooding problems.
\end{abstract}

Keywords: sinkhole drainage, sinkhole shapes, vortex flow, modeling, simulation.

\author{
Povzetek \\ UDK 556.34:519.216 \\ Malcolm S. Field: Simulacija odtoka iz poplavljenega poži- \\ ralnika
}

Razumevanje sposobnosti odtoka iz požiralnikov ter njihovo delovanje je odločilno za zavedanje o učinkih, ki jih lahko povzroči usmeritev odvajanja meteornih voda vanje. $\mathrm{V}$ tem članku so pregledane osnove odvajanja požiralnikov v smislu točkovnega vrtinčastega toka, ki ga ustvari odtok skozi ponikev. Nato so predstavljene številne različne, relativno enostavne oblike požiralnikov ter izdelani matemačni modeli $\mathrm{z}$ namenom simulacije odtoka. Modeli obravnavajo hitrost odtoka v odvisnosti od oblike in omočenega preseka požiralnika, nivoja vode in časa. Modelske simulacije nudijo razumevanje občutljivosti požiralnikov na količino priliva ter spremembe vodne gladine $s$ časom. Pomembnejše ugotovitve vključujejo vpogled v hitrost, s katero lahko pritekanje povečuje nivo vode v požiralniku, ter pomembnost oblike in prereza požiralnika, ki sta povezani $\mathrm{z}$ vrednostjo odtoka. Numerična rešitev je povsem splošna in dovoljuje spreminjaje pritočnih vrednosti na poljuben način. Aplikacija modela na resnične požiralnike lahko pripomore $\mathrm{k}$ ravnanju ob težavah pri poplavah požiralnikov.

Ključne besede: odvajanje požiralnika, oblike požiralnika, vrtinčasti tok, modeliranje, simulacija.

\section{INTRODUCTION}

Sinkholes act as natural surface-water drains, but their enhanced-use by land developers to control stormwater is also common. In recent years there has been some recognition of the potential risks of directing stormwater to sinkholes for drainage (e.g., they may cause additional sinkhole development).
Understanding flow processes on the surface and in the subsurface of karstic terranes is of considerable importance. Most efforts to understand surface flows use traditional hydrological methods and involve peak discharge calculations (see, for example, MDE 2000, Appendix D.10). However, investigations of subsurface

${ }^{1}$ U.S. Environmental Protection Agency, National Center for Environmental Assessment (8623P), 1200 Pennsylvania, Ave., N.W., Washington, D.C. 20460, e-mail: field.malcolm@epa.gov

Received/Prejeto: 4.3.2010 
flows are usually accomplished using a combination of typical aquifer-investigative techniques (e.g., potentiometric-surface mapping and aquifer testing), spring hydrograph assessment and groundwater tracing from selected input points (e.g., sinking streams and sinkholes) to discharge points (e.g., springs and/or wells). Although beneficial in establishing the overall flow picture, these techniques seldom provide adequate details regarding the true nature of the flow between the input and output points. Little attention seems to be directed towards sinkhole-drainage capabilities and functioning, which is critical when intending to direct stormwater drainage to a sinkhole. Reese et al. (1997) briefly allude to an assessment of sinkhole-drainage capacity, but their assessment is limited in scope.

Sinkholes have been described as funnels to a watersupply line (Field 1989). Whatever gets washed down a sinkhole also enters the subsurface solution conduits and is eventually discharged at a downgradient resurgence if constrictions in the conduit do not trap it. Tapping solution conduits or springs for drinking water can pose a health risk. Sinkhole flooding also has obvious implications for local communities (Crawford 1984; Dinger \& Rebmann 1986; Reeder \& Crawford 1988; Reese et al. 1997) including litigation (Quinlan 1984).

Although the risk of dangerous substances getting washed into sinkholes is very real, it is still common practice to direct stormwater runoff into sinkholes to control flooding and hopefully to prevent additional sinkhole occurrences. However, drastically changing surface and/or subsurface hydrology tends to induce the development of new sinkholes. Investigations into directing stormwater drainage down a sinkhole usually entail little more than determining how to redirect surface water to it. There is some indication, however, that local government policies are now slowly moving away from directing stormwater down existing sinkholes (Parizek
2005) and developing more comprehensive stormwater management plans specific to karst terranes (Barner 1999). According to Fleury (2009, p. 21), stormwater management ordinances are a result of communities recognizing the need to better protect their water quality and minimize the risk of inducing new sinkholes. Ordinances occasionally require that sinkhole-drainage capacity be determined, but guidance on how to make such a determination is not easily found (CSN 2009), although there are some general sources that refer to the significance of karstic terranes (see, for example, MDE 2000; MPCA 2008).

Sinkholes have also been described as diagnostic of karst (Quinlan, pers. comm.) and/or as the fundamental unit of karst relief (Sweeting 1973, p. 44). Thus, if sinkholes are evident in the area, then the area is karstic. However, the reverse is not necessarily true; the absence of sinkholes does not rule out karst (Ford \& Williams 2007, p. 339). Sinkhole occurrence, distribution, and formation have all been the subject of extensive studies for many decades (e.g., Cvijić 2005; Ford 1963; Jennings 1985; Sweeting 1973; Williams 1971, 1983, 1985; Gao 2002) as have been the construction aspects of building on sinkholes (e.g., Sowers 1996; Waltham et al. 2005). Some research efforts have also been directed towards better stormwater-quality management when the intent is to use sinkholes for stormwater drainage (Crawford \& Groves 1995; Kalmes \& Mohring 1995; Keith et al. 1995). However, little research appears to have been directed at understanding sinkhole-drainage functioning.

In an effort to obtain a better understanding of how sinkholes function, this paper describes a model for sinkhole drainage and provides some idealized simulations. The model was developed to simulate the flow into and through a sinkhole of moderate dimensions that is drained by a swallet. The model is limited to theoretical conditions because of various simplifying assumptions.

\section{SINKHOLE-DRAINAGE HYDROLOGY}

Drainage through the bottom of a sinkhole swallet is of particular interest to local managers when the underlying swallet becomes plugged or inflow exceeds the drainage capacity of the swallet because the sinkhole will tend to become temporarily flooded until either inflows are reduced or sufficient pressure is developed such that the plug is forced down the swallet. Waltham et al. (2005, p. 251-253) provide a brief discussion of the causes of sinkhole flooding and the need to address the problem. Zhou (2007) provides a more comprehen- sive discussion of the causes for sinkhole flooding and the need to recognize the physical processes of sinkhole drainage. According to Zhou, the main causes for sinkhole flooding are (1) excessive recharge to the sinkhole (inadequate drainage capacity), (2) excessive inflows (inadequate conduit capacity), and (3) inadequate discharge (flow restrictions at distal springs). Soil-plugged sinkholes, which fall under the category of excessive recharge defined by Zhou, are quite common as evidenced by the example of a dropout doline schematically shown 
in Fig. 2 of Waltham \& Lu (2007, p. 15). Plug removal may result in a large pulse of water draining out of the sinkhole that may impact downstream water supplies as well as possibly cause some structural damage. Modeling sinkhole drainage can provide insights into sinkhole functioning and perhaps lead to better stormwater management of sinkholes.

\section{SWALLET-CAPACITY DETERMINATION}

The most important hydrologic aspect of a sinkhole is its swallet capacity (Milanović 2004, p. 22). This is the subject of a detailed discussion in Bonacci (1987, p.
2007). As explained by Bonacci (1987, p. 109), the swallet capacity $q$ depends on the water level $h$ in the pre-swallet retention only when flow in the underlying main karst channel is not under pressure; when under pressure the swallet capacity is dependent on head differences. Swallet drainage is defined by Torricelli's theorem (Streeter \& Wylie 1979, p. 104) according to

$$
q(h)=a \pi c_{0} \sqrt{2 g h},
$$

which states that drainage from a sinkhole depends on the height $h$ of water above the swallet, but assumes no friction, which would be insignificant at small flow velocities (Bögli 1980, p. 88). The discharge coefficient $c_{0}$ represents the ratio of the actual discharge to that computed from the full area $a$ of the opening and the ideal velocity (Schoder \& Dawson 1934, p. 130). Bonacci (1987, p. 110) used equation (1) and others to provide a general estimate for the swallet capacity for various sinkholes. However, extensive potentiometric measurements are required to determine, for example, the value of $c_{0}$.

\section{THEORY OF SINKHOLE DRAINAGE}

Drainage of a flooded sinkhole via a swallet takes place by point vortex flow. Pozrikidis (2001) provides a comprehensive theoretical discussion of vortex motion (e.g., p. 288-295, 548-605); see also Ogawa (1993) and Majda and Bertozzi (2008). On the basis of the methods described in Pozrikidis, Fig. 1 shows the counterclockwise velocity field created by 109-115) because poor swallet drainage often results in massive flooding when capacities are exceeded (see Fig. 5.8, in Bonacci 1987). Loss of life, serious injury and displacement, and damage to homes and other structures often occur as a result of flooding in karstic terranes (Day a point vortex representing the swallet of a symmetrical circular sinkhole or elliptical sinkhole.

For those instances in which the swallet is offset from the center of the sinkhole (Figs. $1 \mathrm{~b}$ and $1 \mathrm{~d}$ ), a velocity field and its image may be calculated at any point 
within the vortex. The velocity field was calculated at the tip of the arrow depicting the counterclockwise vortex flow shown in Figs. $1 \mathrm{~b}$ and $1 \mathrm{~d}$. The negative velocity field values indicate the counterclockwise flow induced by the primary point vortex centered over the swallet.

For a circular sinkhole (Figs. 1a and $1 \mathrm{~b}$ ) the velocity induced by the image point vortex may be calculated as the latter rotates around the center of the sinkhole in the direction of the polar angle $\theta$ in the counterclockwise direction (Pozrikidis 2001, p. 558). In a circular sinkhole with a centered swallet (Fig. 1a), the dimensionless velocity $v_{\theta}=0$, whereas in a circular sinkhole with an offset swallet (Fig. 1b) the dimensionless velocity $v_{\theta}=0.0756$; $v_{\theta}$ increases as the extent of offset increases.

\section{MODELING SINKHOLE DRAINAGE USING VARIOUS SINKHOLE SHAPES}

Every sinkhole has one or more defined swallets at its base that connects with underlying conduits that discharge at a downstream resurgence. Typically, sinkholes receive both diffuse and concentrated autogenic recharge, which drains into a swallet through a shaft to an underlying solution conduit. Flow through this solution conduit then drains to some downgradient resurgence point.

It is realistic to envision a sinkhole becoming plugged by soil when it first develops, or as a result of construction, increased catchments, or back-flooding from conduits impeded by sediment or breakdown (Waltham et al. 2005, p. 251). When inflows exceed the sinkhole-drainage capacity, the sinkhole fills and overflows. In the case of a swallet plug, the plug will restrict but not necessarily prevent water drainage down the swallet. As the water level rises above the plug, leakage around and through it tends to loosen the compacted soil and lubricate the underlying swallet and consequently, pressure builds up above the plug. Eventually, leakage of water through and around the soil plug, and the pressure gradient from the overlying water, combine to drive the plug down through the swallet so that the flooded sinkhole rapidly drains. Similar leakage and full drainage will occur in the other circumstances described here.

\section{MODEL DESCRIPTION}

Simplified theoretical models for sinkhole drainage can be developed according to the conditions depicted in Fig. 2, in which a sinkhole typically ranges in size from 2-100 $\mathrm{m}$ in depth, $10-1000 \mathrm{~m}$ in diameter, and is commonly circular or elliptical in form (Cvijić 2005, p. 66) as shown in Fig. 1. The model is limited to theoretical conditions because of, for example, the assumption of symmetry of sinkhole shape and viscosities equal to that of water. The model does not address the pressure head necessary to drive a plug down the swallet; rather the model only balances inflow and outflow as related to instantaneous flushing of water down the swallet. The simplified model described here considers flow into and through a funnel (Rostamian 2009) as an analogue for sinkhole drainage. It should be noted that some of the sinkholes depicted in Fig. 2 are not typical. For example, Fig. 2c is uncommon, but undercutting of sinkhole walls does sometimes occur, so it was considered appropriate to include it in the model analysis.

The sinkholes shown in Fig. 2 may be classified according to the three main shapes identified by Cvijic (2005, p. 69). Specifically, Cvijić (2005, p. 70) identified well-shaped sinkholes (cylinder-shaped) that conform to Figs. 2a and 2d, which he regarded as relatively rare. Fig. $2 b$ generally matches the funnel-shaped sinkholes of Cvijić (2005, p. 69) and Fig. 2f generally matches the bowl-shaped sinkholes of Cvijić (2005, p. 69). The remaining sinkholes shown (Figs. 2c and 2e) are exaggerations of sinkholes exhibiting undercutting or other shapes due to hydrologic, geologic, and/or geomorphologic conditions.

Applying Torricelli's theorem to the sinkholes depicted in Fig. 2, drainage through their swallets is related to the water levels in the sinkholes according to

$q(h)=a_{0} c_{0} \sqrt{2 g(h)}$,

where equation (2) differs from equation (1) only by consideration of the dependence of swallet drainage on water level as a function of time, and where

$a_{0}=\pi x_{0}^{2}$.

The volume of water $V$ in the sinkhole at time $t$ varies according to

$\frac{d V}{d t}=Q(t)-q(h)$,

where $d V / d t$ is related to water level $h$ by the wetted cross-sectional area $A(h)$ of the sinkhole at each elevation, according to 

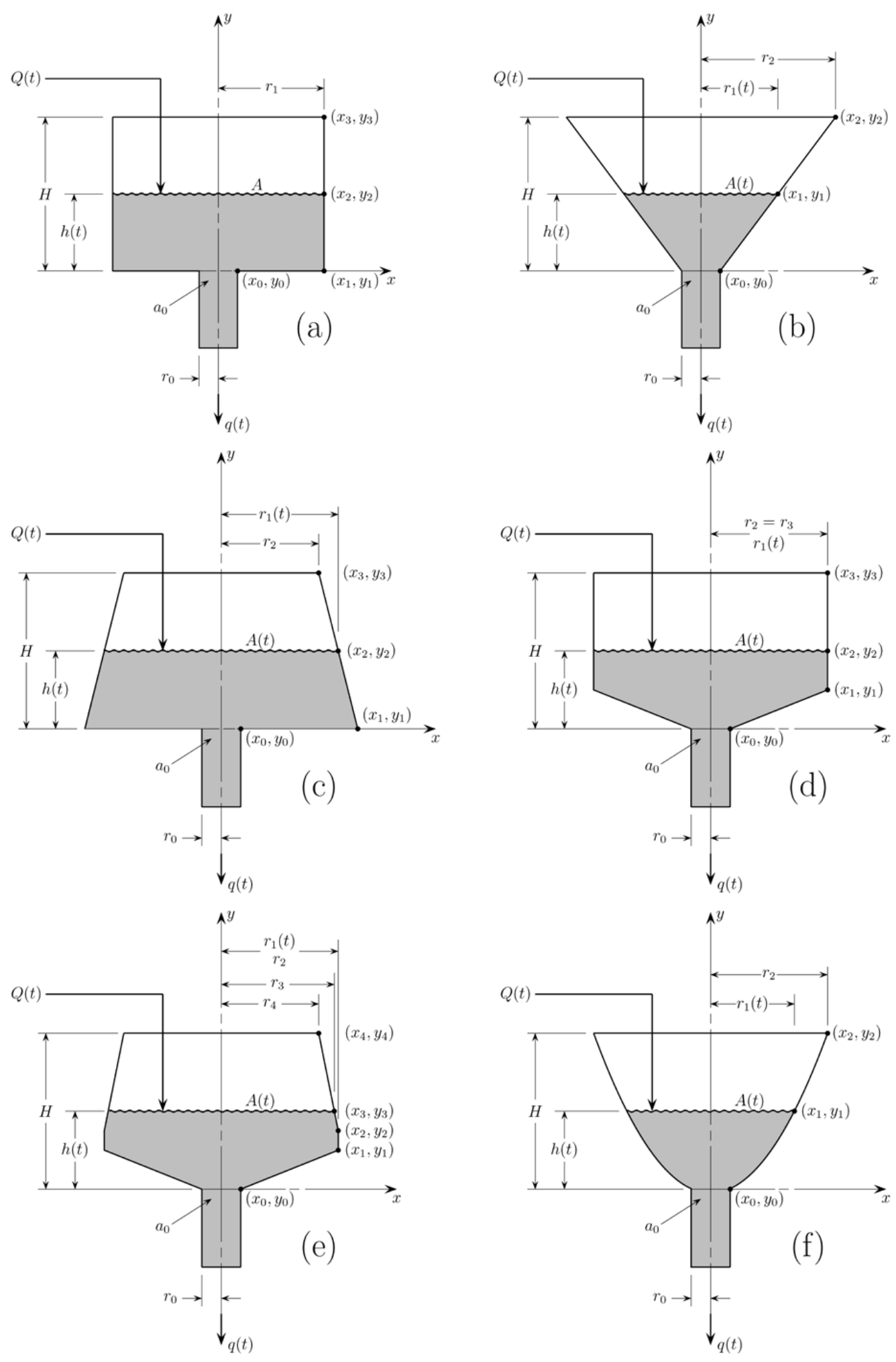

Fig. 2: Schematic diagram and coordinate system depicting flow into and out of a sinkhole: (a) symmetrical cylindrically-shaped sinkhole; (b) symmetrical cone-shaped sinkhole; (c) symmetrical inverted-cone-shaped sinkhole; (d) symmetrical cylindrical-cone-shaped sinkhole; (e) combined symmetrical inverted-cylindrical-cone-shaped sinkhole; and (f) symmetrical bowl-shaped sinkhole. Subscripts greater than 2 are considered equal to 2 in the text for purposes of mathematical simplification. Proportions are not drawn exactly. 


$$
\frac{d V}{d t}=A(h) \frac{d h}{d t}
$$

so that equation (4) now becomes

$$
A(h) \frac{d h}{d t}=Q(t)-q(h) .
$$

An expression for the wetted cross-sectional area $A(h)$ of a sinkhole is easily obtained for a symmetrical, cylindrically-shaped sinkhole as depicted in Fig. 2a that is not dependent on time $t$ or water level $h$. In this case, equation (2) reverts to equation (1) and the wetted crosssectional area of the sinkhole is

$A=\pi r^{2}$

where $r^{2}$ is equivalent to $x y$ and $x=y$ on the circle at the top of Fig. 1. For the ellipse shown on the bottom of Fig. 1 the area is obtained from

$A=\pi x y$,

where $y<x$.

An expression for the wetted cross-sectional area $A(h)$ of a symmetrical cone-shaped sinkhole or inverted cone-shaped sinkhole, however, is a function of the water level $h$ in the sinkhole (a function of time $t$ ) and is accomplished by using the coordinates on the right side of the sinkholes depicted in Figs. $2 \mathrm{~b}$ and $2 \mathrm{c}$

$$
\begin{aligned}
y-y_{0} & =\left(\frac{y_{2}-y_{0}}{x_{2}-x_{0}}\right)\left(x-x_{0}\right) \\
& =\left(\frac{H}{x_{2}-x_{0}}\right)\left(x-x_{0}\right) .
\end{aligned}
$$

Substituting $h(t)$ for $y$ and solving for $x=r(h)$ yields
$r(h)=x_{0}+\left(\frac{x_{2}-x_{0}}{H}\right) h(t)$,

which represents the radius at a given water level $h$ in the sinkhole at time $t\left(r(h)=x_{2}\right.$ for cylindrical walls) so that the wetted cross-sectional area $A(h)$ at time $t$ and water level $h$ may be obtained from

$A(h)=\pi\left[x_{0}+\left(\frac{x_{2}-x_{0}}{H}\right) h(t)\right]^{2}$.

For a symmetrical bowl-shaped sinkhole (Fig. 2f) the wetted cross-sectional area $A(h)$ is easier to determine as a function of water level $h$ because the radius at a specific water level $r(h)$ may be solved using the equation of a parabola. The equation for $r(h)$ is then

$r(h)=\sqrt{\frac{x_{2}^{2}}{H} h(t),}$

and the equation for $A(h)$ becomes

$A(h)=\pi \frac{x_{2}^{2}}{H} h(t)$,

where $x_{2}^{2} / H$ is the reciprocal of the leading coefficient in the equation for a parabola that affects the curvature. Equations (9)-(13) are applicable to sinkholes of circular form and are also applicable to sinkholes of elliptical form after minor modifications.

For an asymmetrical sinkhole, the cross-sectional area calculation must be based on a polygon that represents its shape. This calculation can be accomplished, but a new polygon must be developed for each water-level change $\Delta h$.

The appropriate model for sinkhole drainage for each of the sinkhole shapes shown in Fig. 2 is listed in Tab. 1. Figs. $2 \mathrm{~d}$ and $2 \mathrm{e}$ are special cases using various combinations of equations (6), (7), and (11).

\begin{tabular}{|l|l|}
\hline Sinkhole Shape & Drainage Model \\
\hline Cylindrically-Shaped & Equations (6) and (7) \\
\hline Cone-Shaped & Equations (6) and (11) \\
\hline Inverted Cone-Shaped & Equations (6) and (11) \\
\hline Cylindrical-Cone-Shaped & Equations (6) and (7), (11) \\
\hline Inverted-Cylindrical-Cone-Shaped & Equations (6) and (7), (11) \\
\hline Bowl-Shaped & Equations (6) and (13) \\
\hline
\end{tabular}

Tab. 1: Drainage models for the sinkhole shapes shown in Fig. 2. 


\section{CRITICAL INFLOW RATE}

The critical inflow rate $Q_{c}$ for a sinkhole may be defined as the rate of inflow that maintains a fully filled sinkhole but which does not overflow. For a fully filled sinkhole that is not overtopped, $h(t)=H$ and the depth of the sinkhole is not increasing (e.g., due to geomorphologic processes), $d h / d t=0, d V / d t=0$, and $Q_{c}=q(h)=0$. The critical inflow rate $Q_{c}$ can then be obtained from

$Q_{c}=a \pi c_{0} \sqrt{2 g H}$.
Equation (14) is a slight modification of equation (1) because water level is not changing. Estimating critical inflow rate can be useful for assessments of the potential for flooding hazards when designing stormwater drainage into sinkholes.

The model was solved numerically using a Fortran program and the numerical method of lines (Schiesser 1993). The numerical solution is completely general so it allows for varying inflow rates in any manner desired.

\section{MODEL SIMULATIONS}

Inflow rate into the sinkholes depicted in Fig. 2 is a prime control on sinkhole drainage rate, but not the sole control. This is because the rate of outflow is strongly dependent on the water level $h$ in the sinkhole and the wetted crosssectional area $A(h)$ of the sinkhole as a function of time $t$, all of which are a function of sinkhole shape.

Parameters for a moderately sized circular sinkhole are shown in Tab. 2. Initial inflow rates for the sinkholes were $0.240,0.190,0.147$, and $0.020 \mathrm{~m}^{3} \mathrm{~s}^{-1}$. These four inflow rates were chosen to reflect conditions of extreme inflow exceedance $Q>>q$, inflow exceedance $Q>q$, inflow equality $Q=q$, and extreme inflow inferiority $Q<<q$, all relative to outflow.

\section{UNIFORM INFLOW RATES INTO SINKHOLES}

Uniform inflow into sinkholes does not necessarily translate into a uniform outflow or drainage rate through the swallet at the base of the sinkhole; other hydrological and geological factors not addressed here are also of importance. The model developed herein was initially tested using the listed series of four uniform inflow rates. Inflow rates were chosen to reflect the influence of inflow on drainage rate while still allowing the initial static water level $h$ in the sinkholes to respond with time as a result of the swallet either being overwhelmed by the inflowing water or completely draining the inflow so no water stands in the sinkhole.

\section{Uniform Inflow-Water-Level Changes}

Simulation results for water level $\Delta h$ as a function of time $t$ for a uniform inflow of water into the sinkholes depicted in Fig. 2 are shown in Fig. 3. The water level $h$ in all of the sinkholes depicted in Fig. 3 varies significantly
Tab. 2: Parameters for modeling the various circular sinkhole shapes depicted in Fig. 2.

\begin{tabular}{|l|l|c|}
\hline Parameter & Value & Units \\
\hline Sinkhole Factors & & \\
\hline Sinkhole Height & 6.00 & $\mathrm{~m}$ \\
\hline Sinkhole Radius & 3.00 & $\mathrm{~m}$ \\
\hline & & \\
\hline Swallet Factors & & $\mathrm{m}$ \\
\hline Swallet Height & 0.00 & $\mathrm{~m}$ \\
\hline Swallet Radius & 0.10 & \\
\hline Coef. Of Discharge & 0.61 & \\
\hline & & $\mathrm{m}$ \\
\hline Initial Conditions & & \\
\hline Water Level & 3.00 & $\mathrm{~m}^{3} \mathrm{~s}^{-1}$ \\
\hline Inflow Rate $Q^{\mathrm{a}, \mathrm{b}}$ & & $\mathrm{m}^{3} \mathrm{~s}^{-1}$ \\
\hline$Q>>q$ & 0.240 & $\mathrm{~m}^{3} \mathrm{~s}^{-1}$ \\
\hline$Q>q$ & 0.190 & $\mathrm{~m}^{3} \mathrm{~s}^{-1}$ \\
\hline$Q=q$ & 0.147 & \\
\hline$Q<<q$ & 0.020 & \\
\hline
\end{tabular}

${ }^{a}$ Model simulations were conducted with four selected initial inflow rates to reflect the specific chosen conditions. Critical inflow rate $Q_{c}=0.208 \mathrm{~m}^{3} \mathrm{~s}^{-1}$ for the sinkhole parameters used here.

${ }^{\mathrm{b}}$ Critical inflow rate $Q_{c}=0.208 \mathrm{~m}^{3} \mathrm{~s}^{-1}$ for the sinkhole parameters used here.

and rapidly with respect to time $t$ as water drains through the underlying swallet. The two inflow rates that initially exceed the outflow rate $\left(0.240\right.$ and $\left.0.190 \mathrm{~m}^{3} \mathrm{~s}^{-1}\right)$ rise rapidly in all the model sinkholes. However, the $0.240 \mathrm{~m}^{3} \mathrm{~s}^{-1}$ inflow rate rises more rapidly and overflows the sinkhole to result in overland flooding. The height of the water 
rise above the sinkhole for an inflow rate of $0.240 \mathrm{~m}^{3} \mathrm{~s}^{-1}$ could significantly influence the rate of outflow through the swallet if barriers inhibit the spread of water around the sinkhole, so that ponding produces a greater pressure head. Figs. $3 \mathrm{c}$ and $3 \mathrm{e}$ depict a slower rise in water level because of the wider cross-sectional area $A$ at their base (see Figs. $2 \mathrm{c}$ and $2 \mathrm{e}$ ).

For a receding flood, an inflow rate much less than the drainage capacity $\left(0.020 \mathrm{~m}^{3} \mathrm{~s}^{-1}\right)$, the water level $h$ drops rapidly with respect to time $t$. Figs. $3 \mathrm{c}$ and $3 \mathrm{e}$ exhibit decreasing water levels that differ from the other model sinkhole plots. Fig. $3 \mathrm{c}$ reflects a smoothly decreasing water level that results from the increasing cross-sectional area $A$ as a function of changing water level $\Delta h$, whereas Fig. 3e exhibits a mild hump in the decreasing water level that reflects the change in cross-sectional area $A$ as a function of changing water level $\Delta h$ (see Figs. 2c and $2 \mathrm{e}$ ).

As expected, for the special case of $Q=q\left(0.147 \mathrm{~m}^{3} \mathrm{~s}^{-1}\right)$ there is no apparent change in water level. This is a crucial value for sinkhole drainage because it reflects a transition from $Q<q$ to one of $Q>q$ and should elicit concern from stormwater managers when this rate is exceeded, because the sinkhole will begin filling and may approach the critical inflow rate.

In terms of sinkhole shapes, it is interesting to note the similarity between all the plots shown in Fig. 3. There are some minor differences, but overall the plots all reflect the same basic behavior.

\section{Uniform Inflow-Sinkhole Drainage Rate}

Drainage rate $q$ for uniform inflow rates with respect to $t$ is shown in Fig. 4. These plots resemble those in Fig. 3. In each plot, each inflow rate reflects the importance of water level $h$ in the sinkhole. As water level $h$ changes, drainage rate changes accordingly as expected from equation (2). Also, from Fig. 4 it can be noted that an inflow rate of $0.020 \mathrm{~m}^{3} \mathrm{~s}^{-1}$ becomes asymptotic with the $\mathrm{x}$-axis as expected from equation (6). An inflow rate less than $0.020 \mathrm{~m}^{3} \mathrm{~s}^{-1}$ results in complete drainage of the sinkhole (i.e., $h=0$ ).

\section{Uniform Inflow-Cross-Sectional Area}

The cross-sectional areas for uniform inflow rates developed from the simulations are shown in Fig. 5, which strongly reflects the various shapes of the various sinkholes shown in Fig. 2. Figs. 5a and 5d mostly display a static cross-sectional area for the four different inflow rates. However, for an inflow rate of $0.020 \mathrm{~m}^{3} \mathrm{~s}^{-1}$, the cross-sectional area for the cylindrical-cone-shaped sinkhole (Fig. 5d) rapidly drops to near zero because this particular inflow rate is the only inflow rate that is low enough to allow the water level in the sinkhole to decrease to the part of the sinkhole that becomes cone shaped $(0.9 \mathrm{~m})$. These plots emphasize the relationship of cross-sectional area to water-level changes.

Plots of the cross-sectional areas shown in Figs. 5c and $5 \mathrm{e}$ are complex and reflect the less uniform sinkhole shapes shown in Figs. $2 c$ and 2e. Fig. $2 c$ is an inverted cone, so cross-sectional area increases as water level decreases, which causes an inverse response with respect to inflow rate (i.e., increasing inflow rate results in decreasing cross-sectional area). This effect does not occur in the sinkhole shown in Fig. 2e; rather, the crosssectional area of the sinkhole increases at first and then rapidly falls to zero. This only occurs at the lowest inflow rate because this is the only inflow rate that results in a water level that decreases to an elevation where the change in sinkhole shape influences cross-sectional area. The flattening of the $0.240 \mathrm{~m}^{3} \mathrm{~s}^{-1}$ inflow rate indicates that the top of the sinkhole was breached after about $1500 \mathrm{~s}$.

\section{VARYING INFLOW RATES INTO THE SINKHOLES}

Typical inflow rates would not be expected to be uniform as, for example, in a storm that produces a time-varying inflow rate. Tab. 3 depicts an increasing and then decreasing inflow rate into sinkholes. Although increasing and then decreasing inflow rates shown in Tab. 3 are relatively simple, this simulation serves to illustrate the effects of varying inflow rates.

Tab. 3: Increasing and then decreasing inflow rates used to model sinkhole drainage.

\begin{tabular}{|c|c|c|c|c|}
\hline \multirow{2}{*}{ Time, $s$} & \multicolumn{4}{|c|}{ Inflow Rates, $Q_{\sigma^{\prime}} \mathbf{m}^{3} \mathbf{s}^{-1}$} \\
\cline { 2 - 5 } & $Q_{1}>>q$ & $Q_{2}>q$ & $Q_{3}=q$ & $Q_{4}<<q$ \\
\hline $0^{a}$ & 0.240 & 0.190 & 0.147 & 0.020 \\
\hline 400 & 0.246 & 0.193 & 0.149 & 0.023 \\
\hline 800 & 0.250 & 0.196 & 0.150 & 0.027 \\
\hline 1200 & 0.254 & 0.199 & 0.152 & 0.030 \\
\hline 1600 & 0.258 & 0.202 & 0.154 & 0.033 \\
\hline 2000 & 0.262 & 0.205 & 0.155 & 0.037 \\
\hline 2400 & 0.250 & 0.200 & 0.153 & 0.032 \\
\hline 2800 & 0.237 & 0.194 & 0.149 & 0.028 \\
\hline 3200 & 0.229 & 0.189 & 0.146 & 0.025 \\
\hline 3600 & 0.221 & 0.185 & 0.143 & 0.021 \\
\hline 4000 & 0.213 & 0.180 & 0.140 & 0.018 \\
\hline
\end{tabular}

a Zero time represents initial inflow rates.

Note: Subscripts for discharge $Q_{i}$ refer to the four discharges depicted on Figs. 6, 7, and 8. 


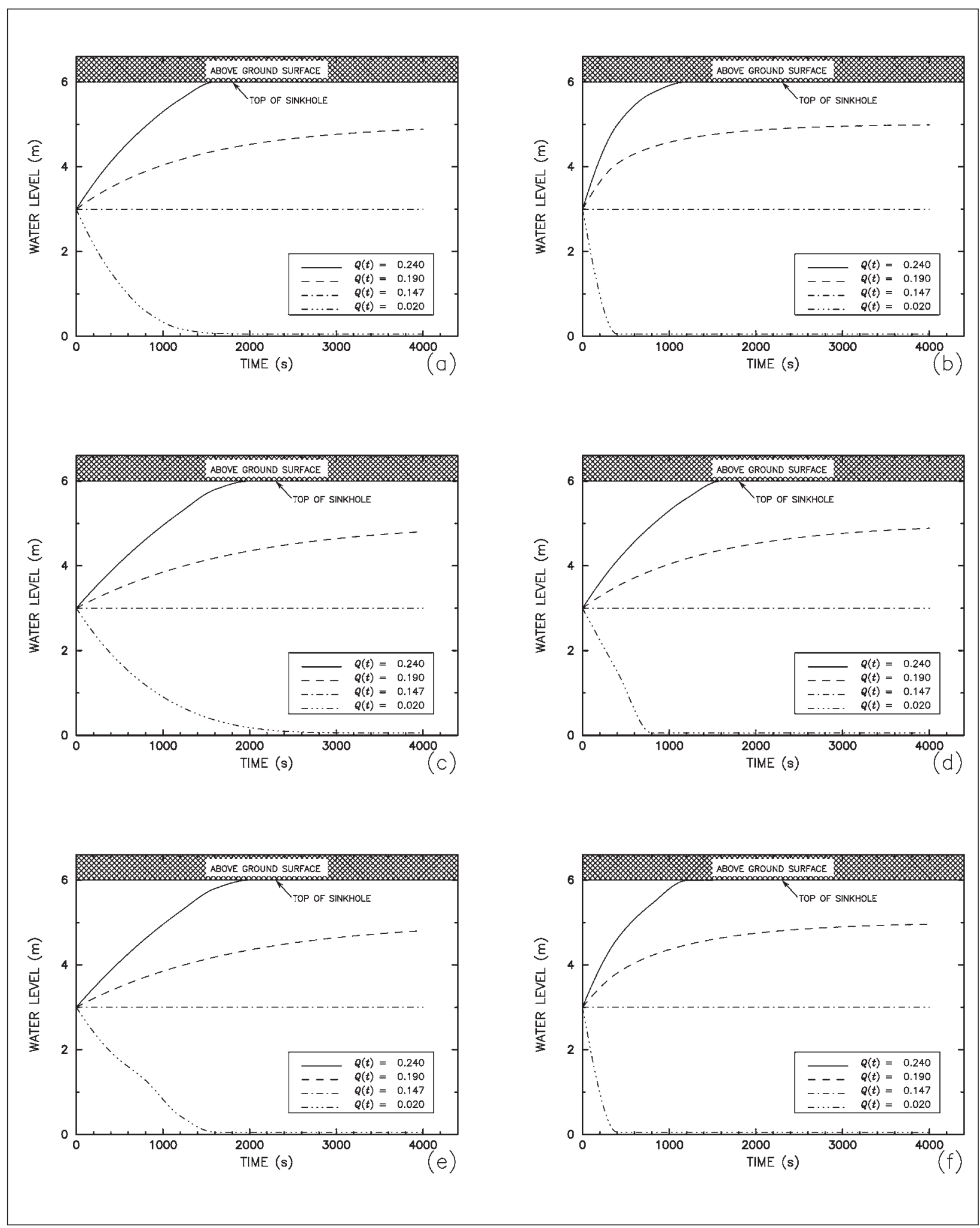

Fig. 3: Graphic plots of calculated water level for each of the six types of sinkhole depicted in Fig. 2 for uniform inflow rates: (a) symmetrical cylindrically-shaped sinkhole; (b) symmetrical cone-shaped sinkhole; (c) symmetrical inverted-cone-shaped sinkhole; (d) symmetrical cylindrical-cone-shaped sinkhole; (e) combined symmetrical inverted-cylindrical-cone-shaped sinkhole; and $(f)$ symmetrical bowl-shaped sinkhole. 

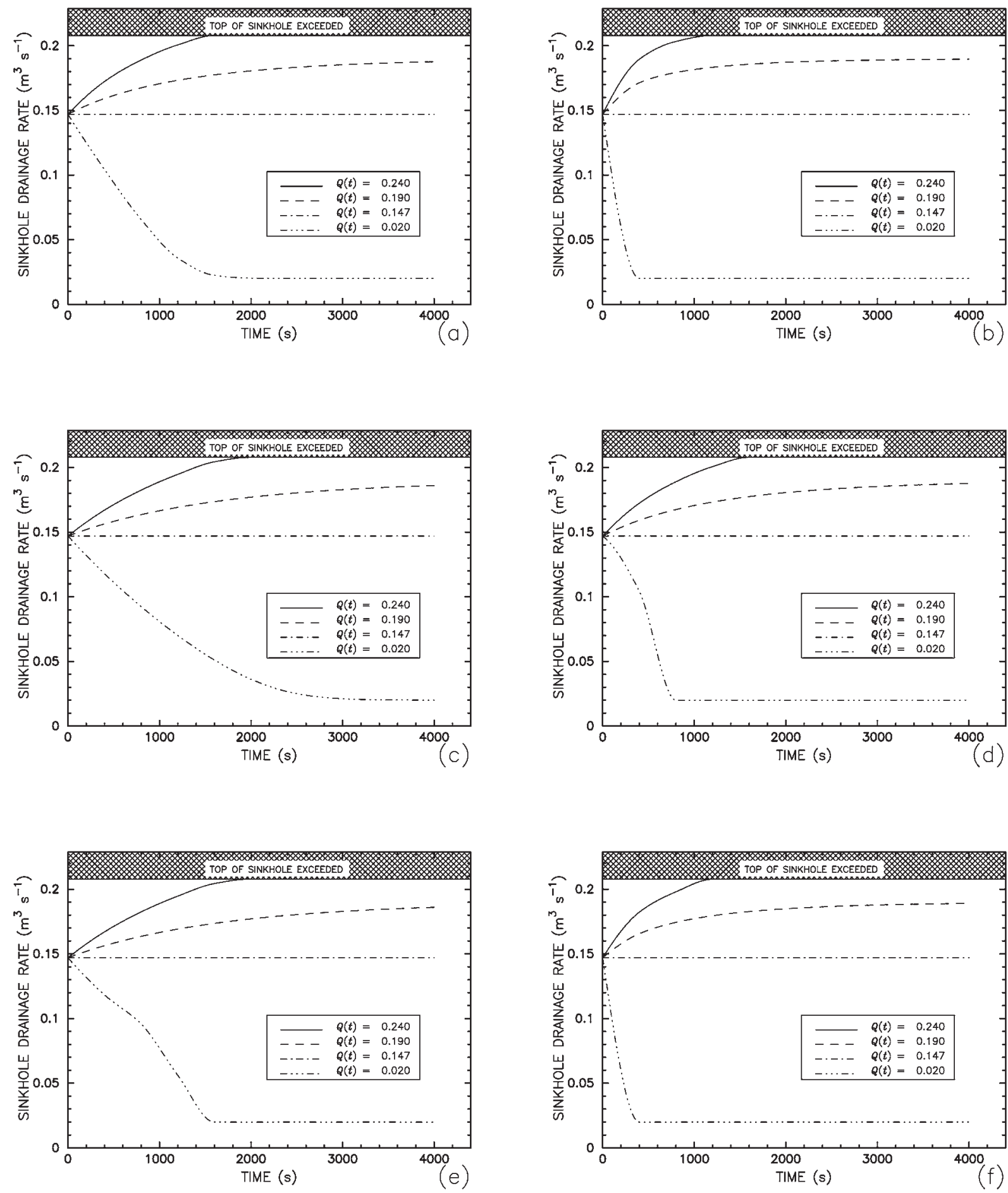

Fig. 4: Graphic plots of calculated drainage rate for each of the six types of sinkholes depicted in Fig. 2 for uniform inflow rates: (a) symmetrical cylindrically-shaped sinkhole; (b) symmetrical cone-shaped sinkhole; (c) symmetrical inverted-cone-shaped sinkhole; (d) symmetrical cylindrical-cone-shaped sinkhole; (e) combined symmetrical inverted-cylindrical-cone-shaped sinkhole; and $(f)$ symmetrical bowl-shaped sinkhole. 


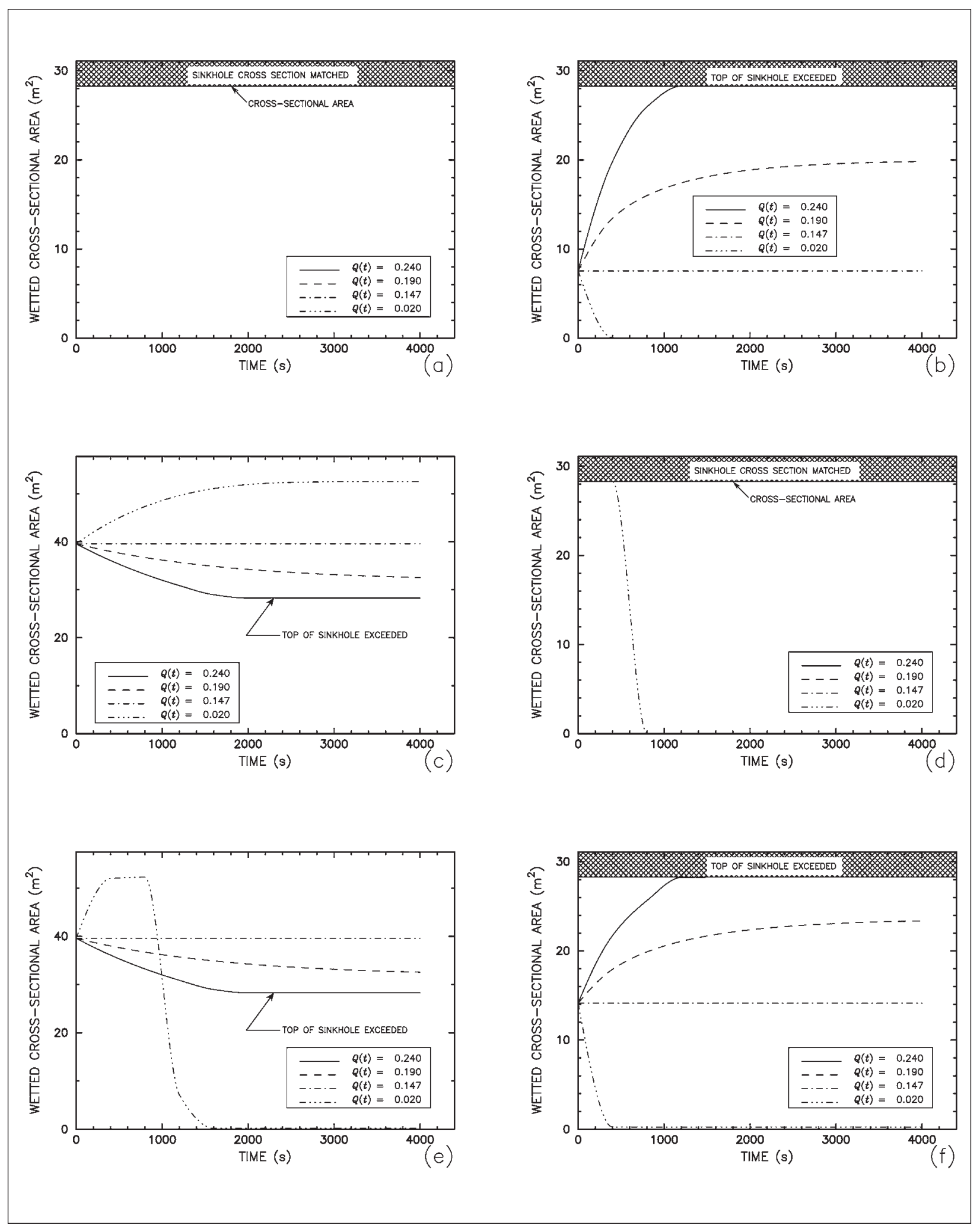

Fig. 5: Graphic plots of calculated wetted cross-sectional area for each of the six types of sinkholes depicted in Fig. 2 for uniform inflow rates: (a) symmetrical cylindrically-shaped sinkhole; (b) symmetrical cone-shaped sinkhole; (c) symmetrical inverted-cone-shaped sinkhole; (d) symmetrical cylindrical-cone-shaped sinkhole; (e) combined symmetrical inverted-cylindrical-cone-shaped sinkhole; and ( $f$ ) symmetrical bowl-shaped sinkhole. 


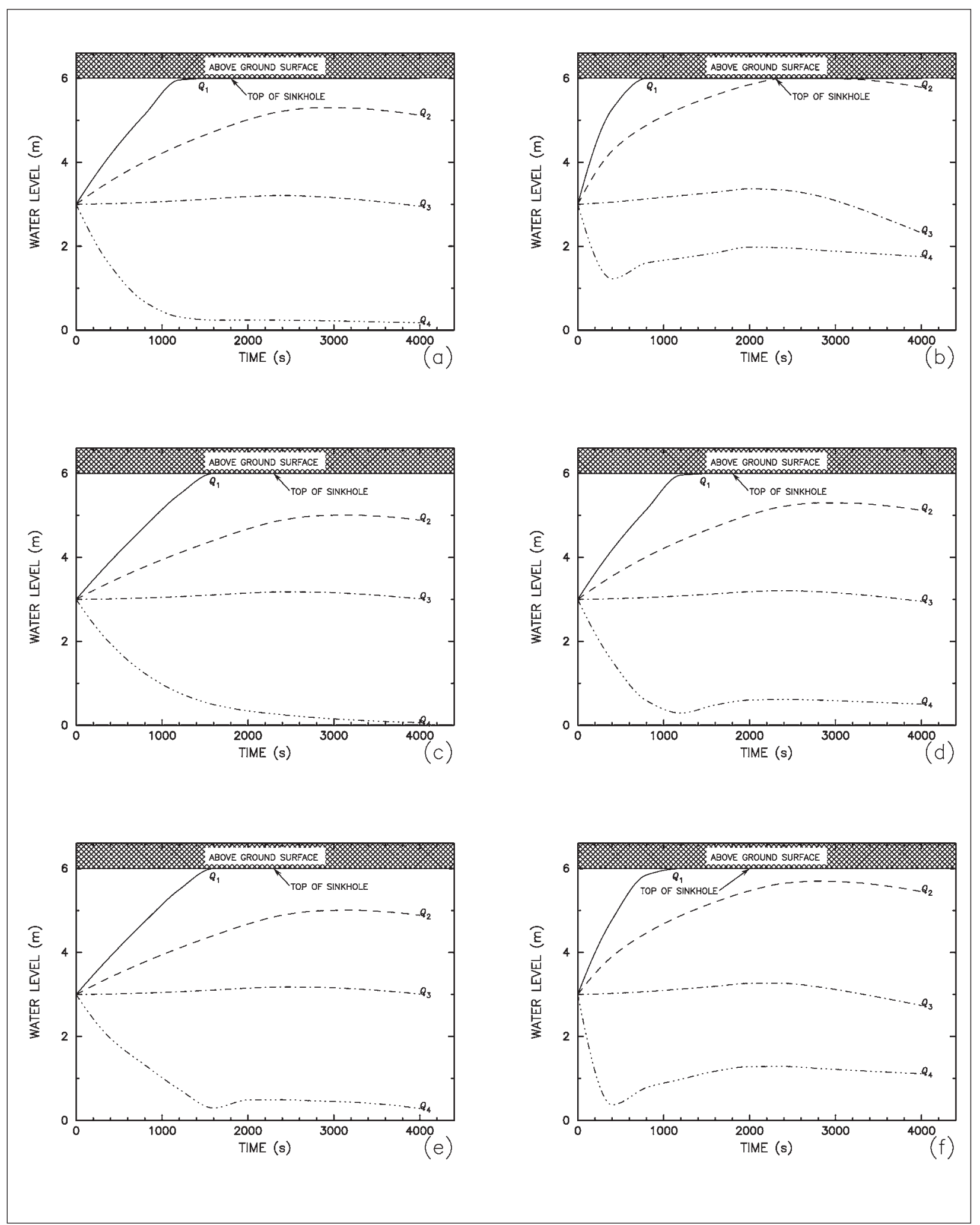

Fig. 6: Graphic plots of calculated water level for each of the six types of sinkholes depicted in Fig. 2 for varying inflow rates: (a) symmetrical cylindrically-shaped sinkhole; (b) symmetrical cone-shaped sinkhole; (c) symmetrical inverted-cone-shaped sinkhole; (d) symmetrical cylindrical-cone-shaped sinkhole; (e) combined symmetrical inverted-cylindrical-cone-shaped sinkhole; and $(f)$ symmetrical bowl-shaped sinkhole. Varying inflow rates $Q_{i}$ with respect to time are provided in Tab. 3. 


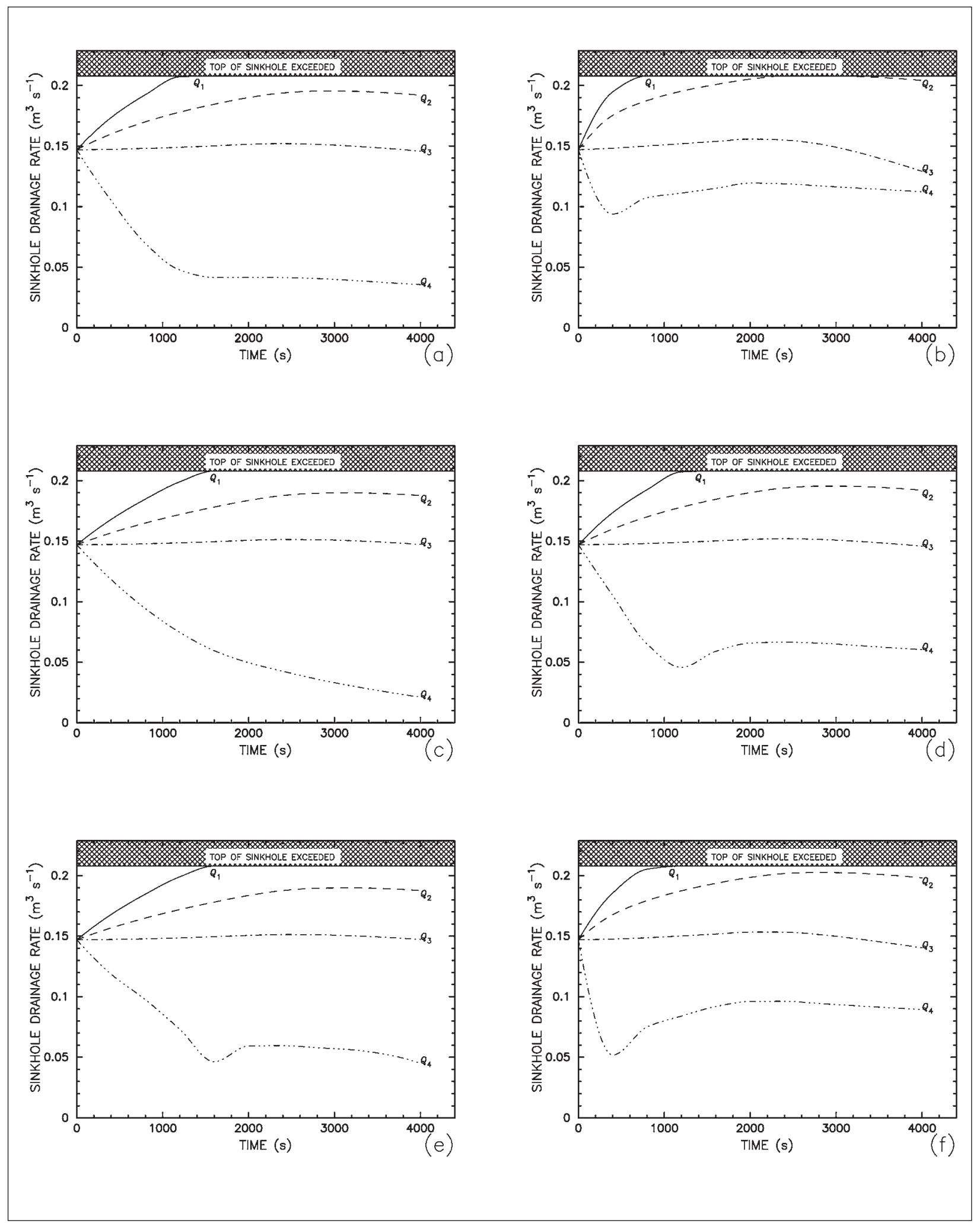

Fig. 7: Graphic plots of calculated outflow for each of the six types of sinkholes depicted in Fig. 2 for varying inflow rates: (a) symmetrical cylindrically-shaped sinkhole; (b) symmetrical cone-shaped sinkhole; (c) symmetrical inverted-cone-shaped sinkhole; (d) symmetrical cylindrical-cone-shaped sinkhole; (e) combined symmetrical inverted-cylindrical-cone-shaped sinkhole; and $(f)$ symmetrical bowl-shaped sinkhole. Varying inflow rates $Q_{i}$ with respect to time are provided in Tab. 3. 


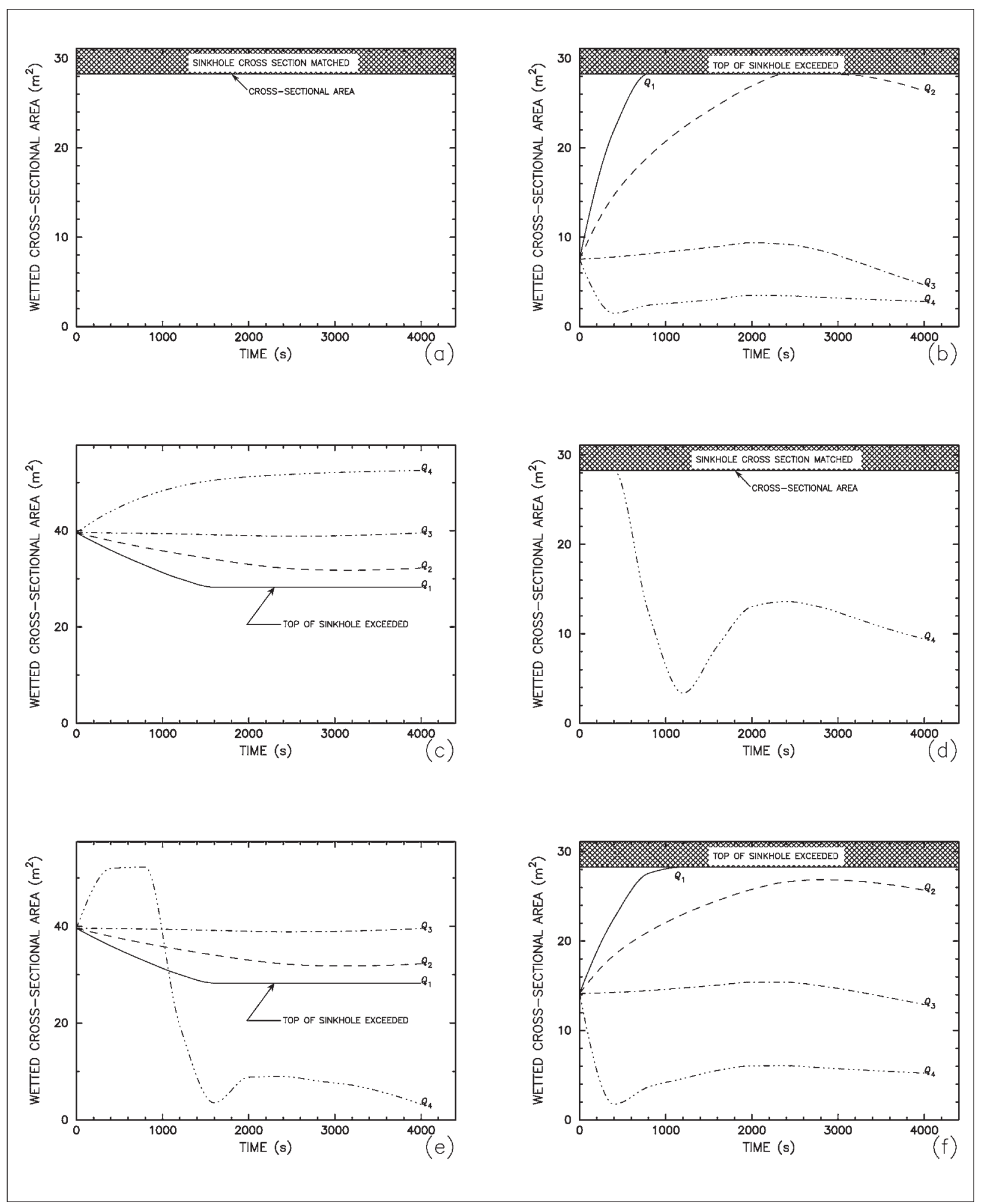

Fig. 8: Graphic plots of calculated wetted cross-sectional area for each of the six types of sinkholes depicted in Fig. 2 for varying inflow rates: (a) symmetrical cylindrically-shaped sinkhole; (b) symmetrical cone-shaped sinkhole; (c) symmetrical inverted-cone-shaped sinkhole; (d) symmetrical cylindrical-cone-shaped sinkhole; (e) combined symmetrical inverted-cylindrical-cone-shaped sinkhole; and ( $f$ ) symmetrical bowl-shaped sinkhole. Varying inflow rates $Q_{i}$ with respect to time are provided in Tab. 3. Note that although no $Q_{i}$ are shown for sinkhole types $(a)$ and $(d)$ because the cross-sectional areas did not vary, the inflow rates did vary according to Tab. 3. 


\section{Varying Inflow-Water-Level Changes}

The water levels shown in Fig. 6 show the effect of first increasing and then decreasing inflow rates. In general, these curves are similar to those shown in Fig. 3, but with some apparent differences. For example, all of the six sinkholes depicted in Fig. 2 show the water level for the greatest inflow rate $0.240 \mathrm{~m}^{3} \mathrm{~s}^{-1}$ exceeding the top of the sinkhole, but one also shows the inflow rate of $190 \mathrm{~m}^{3} \mathrm{~s}^{-1}$ exceeding the top of the cone-shaped sinkhole (Fig. 2b) and then later receding below the top of the sinkhole (Fig. 6b).

For initial inflow rates of 0.147 and $0.020 \mathrm{~m}^{3} \mathrm{~s}^{-1}$, water levels fluctuate as expected. In general, water levels initially increase for the $0.147 \mathrm{~m}^{3} \mathrm{~s}^{-1}$ inflow rate and then decrease. However, for the $0.020 \mathrm{~m}^{3} \mathrm{~s}^{-1}$ inflow rate, other than for the inverted sinkhole (Fig. 2c), water levels initially fall significantly, then rise, and then begin declining slightly. Only the inverted sinkhole exhibits a smooth and steady decline for the $0.020 \mathrm{~m}^{3} \mathrm{~s}^{-1}$ inflow rate (Fig. 6c).

\section{Varying Inflow-Sinkhole Drainage Rate}

As expected, the plots of drainage rate (Fig. 7) generally mimic the appearance of the varying water level plots (Fig. 6). This occurs because of the defined relationship (equation (2)) between water level and drainage rate.

\section{Varying Inflow-Cross-Sectional Area}

Simulation plots of cross-sectional area $A$ with respect to time $t$ emphasize the importance of sinkhole shape in the model. Figs. $8 \mathrm{a}$ and $8 \mathrm{~d}$ exhibit no change in crosssectional area for the three greatest inflow rates because in Figs. 8a and 8d the sinkholes are both mainly cylindrical; the plot in Fig. 8d varies near the bottom of the sinkhole, which is reflected in the erratic shape for the smallest inflow rate. Because inflow rate initially increases, the rate of decrease is insufficient within the allotted time $(t=4000 \mathrm{~s})$ for the water level for the three greatest inflow rates to fall to the elevation where the sinkhole changes to cone shaped in Fig. 8d. Fig. 8e is similar to Fig. $5 \mathrm{e}$ because of the odd shape of the sinkhole shown in Fig. 2 e, but the varying inflow rate for the smallest inflow rate adds some complexity.

Cone- and bowl-shaped sinkholes (Fig. 2b and 2f) exhibit similarly shaped irregular cross-sectional areas (Figs. 8b and 8f). For the extreme inflow rates $Q>q$ it can be seen in Fig. $8 \mathrm{~b}$ that the maximum cross-sectional areas were exceeded because the top of the sinkhole was exceeded in each instance. However, for the $0.190 \mathrm{~m}^{3} \mathrm{~s}^{-1}$ inflow rate, Fig. $8 \mathrm{~b}$ also shows that once the water level falls below the top of the sinkhole, the cross-sectional area is no longer too limited for the rate of inflow.

\section{CONCLUSIONS}

The sinkhole-drainage simulations developed in this paper illustrate the sensitivity of swallets to varying inflow rates. Drainage rate is shown to be primarily a function of water level in the sinkhole, but also as a function of sinkhole shape, cross-sectional area, swallet diameter, and time. These models show an appropriate approach to the prediction of sinkhole flooding and the variables that must be considered in this prediction.

The significance of sinkhole and swallet dimensions for sinkhole drainage emphasizes the need to take care- ful measurements of the basic hydrologic and geologic parameters so that drainage capabilities of the sinkhole may be reasonably estimated. Such an estimate will not necessarily lead to inflow restrictions that will prevent expansion of the sinkhole or new sinkhole development. However, minimizing sinkhole-flooding hazard may be achieved if sinkhole-drainage capacity and functioning is reasonably well understood and appropriate stormwater-management plans implemented.

\section{ACKNOWLEDGMENTS}

The author would like to thank Dr. William Schiesser of Lehigh University and Dr. Arthur Palmer and Marga- ret Palmer of the State University of New York for their respective reviews of this manuscript and their advice. 
Their guidance and assistance over the years are greatly appreciated. The author also thanks Michael Eller of the U.S. Environmental Protection Agency for his careful review and comments of an early draft of my manuscript.

\section{NOTATIONS}

$A$ wetted cross-sectional area of sinkhole $\left[\mathrm{L}^{2}\right]$

$a \quad$ wetted cross-sectional area of swallet $\left[\mathrm{L}^{2}\right]$

$a_{0}$ wetted cross-sectional area times $\pi$ of swallet $\left[\mathrm{L}^{2}\right]$

$c_{0}$ discharge coefficient, equal to the velocity coefficient times the contraction coefficient []

$g$ gravitational acceleration $\left[\mathrm{L} \mathrm{T}^{-2}\right]$

$h$ water level in sinkhole [L]

$H$ height of sinkhole [L]

$Q \quad$ inflow rate into the sinkhole from all sources $\left[\mathrm{L}^{3} \mathrm{~T}^{-1}\right]$
Q critical inflow rate into the sinkhole from all sources such that the sinkhole remains fully filled $\left[\mathrm{L}^{3} \mathrm{~T}^{-1}\right]$

$q$ rate of drainage (discharge) out of the sinkhole $\left[\mathrm{L}^{3} \mathrm{~T}^{-1}\right]$

$r_{0} \quad$ swallet radius $[\mathrm{L}]$

$r_{1}$ radius of sinkhole at water height in sinkhole [L]

$r_{2}$ maximum sinkhole radius [L]

$\stackrel{2}{V}$ volume $\left[\mathrm{L}^{3}\right]$

$x_{i} \quad \mathrm{x}$ (horizontal) coordinates for one side of the sinkhole [L]

$y_{i} \quad \mathrm{y}$ (vertical) coordinates for one side of the sinkhole [L]

\section{REFERENCES}

Barner, W.L., 1999: Comparison of stormwater management in a karst terrain in Springfield, Missouri case histories.- Engineering Geology, 52, 105-112.

Bögli, A., 1980: Karst Hydrology and Physical Seleology.Springer-Verlag, pp. 284, Berlin.

Bonacci, O., 1987: Karst Hydrology with Special Reference to the Dinaric Karst.- Springer-Verlag, pp. 184, Berlin.

Crawford, N.C., 1984: Sinkhole flooding associated with urban development upon karst terrain: Bowling Green, Kentucky.- In: Beck, B.F. (ed.) Proceedings of the sinkholes: Their geology, engineering \& environmental impact conference, $15^{\text {th }}-19^{\text {th }}$ October 1984, Orlando, Florida. A.A. Balkema, 283-292, Boston.

Crawford, N.C. \& C.G. Groves, 1995: Sinkhole collapse and ground water contamination problems resulting from storm water drainage wells on karst terrain.- In: Beck, B.F. (ed.) Proceedings of the karst geohazards: Engineering and environmental problems in karst terrane conference, $2^{\text {nd }}-5^{\text {th }}$ April 2005, Gatlinburg, Tennessee. A.A. Balkema, 257-264, Brookfield, Vermont.

CSN, 2009: Stormwater design guidelines for karst terrainin the chesapeake bay watershed, version 2,0, CSN Technical Bulletin No. 1: Chesapeake, Va., Chesapeake Stormwater Network, Karst Working Group.
Cvijić, J., 2005: Karst: A geographic monograph [Translation of Ph.D. Dissertation (1895) Das Karstphänomen, Versuch einer morphologischen Monographie].- In: Stevanović, Z. \& Mijatović, B. (eds.) Cvijić and Karst. Serbian Academy of Science and Arts (SASA) and its Board on Karst Hydrology and ZUHRA, pp. 57-146, Belgrade, Serbia.

Day, M.J., 2007: Hazards in the karst of Jamaica.- In: Parise, M.\& J. Gunn (eds.) Natural and Anthropogenic Hazards in Karst Areas: Recognition, Analysis, and Mitigation. The Geological Society of London, pp. 173-184, London, U.K. [doi:10.1144/SP279.14]

Dinger, J.S. \& J.R. Rebmann, 1986: Ordinance for the control of urban development in sinkhole areas in The Blue Grass Region, Lexington, Kentucky.- In: Crawford, N.C. \& J.F. Quinlan (eds.) Proceedings of the environmental problems in karst terranes and their solutions conference, $28^{\text {th }}-30^{\text {th }}$ October 1986, Bowling Green, Kentucky. National Water Well Association, 163-180, Dublin, Ohio.

Field, M.S., 1989: The vulnerability of karst aquifers to chemical contamination. In: Zaporozec, A. (ed.) Recent Advances in Ground-Water Hydrology, $16^{\text {th }}$ $-19^{\text {th }}$ November 1988, Tampa, Florida. American Institute of Hydrology (AIH), 130-142, Minneapolis, Minn. 
Fleury, S., 2009: Land Use Policy and Practice on Karst Terrains: Living on Limestone.- Springer, pp. 187. [doi:10.1007/978-1-4020-9670-9]

Ford, D., 1963: Aspects of the geomorphology of the Mendip Hills.- Ph.D. thesis. Oxford University.

Ford, D. \& P. Williams, 2007: Karst Hydrogeology and Geomorphology.- John Wiley \& Sons, Ltd, pp. 562, West Sussex, U.K.

Gao, Y., 2002: Karst feature distribution in southeastern Minnesota: Extending GIS-based database for spacial analysis and resource management.- Ph.D. thesis. University of Minnesota, pp. 210.

Jennings, J.N., 1985: Karst Geomorphology.- Basil Blackwell, Ltd., pp. 293, Oxford.

Kalmes, A. \& E. Mohring, 1995: Sinkhole treatment to improve water quality and control erosion in southeastern Minnesota. In: Beck, B.F. (ed.) Proceedings of the karst geohazards: Engineering and environmental problems in karst terrane conference, $2^{\text {nd }}-5^{\text {th }}$ April 2005, Gatlinburg, Tennessee. A.A. Balkema, 265-272, Brookfield, Vermont.

Keith, J.H., Bassett, J.L. \& J.A. Duwelius, 1995: Modification of highway runoff quality by sinkhole drainage structures, Highway 37 improvement project Lawrence County, Indiana.- In: Beck, B.F. (ed.) Proceedings of the karst geohazards: Engineering and environmental problems in karst terrane conference, $2^{\text {nd }}-5^{\text {th }}$ April 2005, Gatlinburg, Tennessee. A.A. Balkema, 273-284, Brookfield, Vermont.

Majda, A.J. \& A.L. Bertozzi, 2008: Vorticity and Incompressible Flow.- Cambridge University Press, pp. 545, Cambridge, U.K.

MDE, 2000: Maryland stormwater design manual: Baltimore, Maryland Department of the Environment.[Online] Available from: http://www.mde.state. md.us/Programs/WaterPrograms/SedimentandStormwater/stormwater_design/ index.asp [Accessed $17^{\text {th }}$ June 2009].

Milanović, P.T., 2004: Water Resources Engineering in Karst.- CRC Press., pp. 312, Boca Raton, Florida.

MPCA, 2008: The Minnesota stormwater manual: Minneapolis-St. Paul, Minnesota Pollution Control Agency.- [Online] Available from: http://www.pca. state.mn.us/publications/wq-strm9-01.pdf [Accessed $17^{\text {th }}$ June 2009].

Ogawa, A., 1993: Vortex Flow.- CRC Press, pp. 311, Boca Raton, Florida.
Parizek, R.R., 2005: Opportunities to enhance management of karstic aquifers.- In: Stevanović, Z. \& B. Mijatović (eds.) Water Resources and Environmental Problems in Karst, Proceedings of the International Conference and Field Seminar, $13^{\text {th }}-19^{\text {th }}$ September 2005, Belgrade, Kotor. ZUHRA, 231-238, Belgrade, Serbia.

Pozrikidis, C., 1999: Little Book of Streamlines.- Academic Press, pp. 148, San Diego.

Pozrikidis, C., 2001: Fluid Dynamics: Theory, Computation, and Numerical Simulation.- Kluwer Academic Publishers, pp. 675, Boston.

Quinlan, J.F., 1984: Litigious problems associated with sinkholes, emphasizing recent Kentucky cases alleging liability when sinkholes were flooded.- In: Beck, B.F. (ed.) Proceedings of the sinkholes: Their geology, engineering \& environmental impact conference, $15^{\text {th }}$ $-19^{\text {th }}$ October 1984, Orlando, Florida. A.A. Balkema, 293-296, Boston.

Reeder, P.P. \& N.C. Crawford, 1988: Urban storm water runoff: Bowling Green, Kentucky.- In: Quinlan, J.F. (ed.) Proceedings of the second conference on environmental problems in karst terranes and their solutions, $16^{\text {th }}-18^{\text {th }}$ November 1988 , Nashville, Tennessee, National Water Well Association, 69-95, Dublin, Ohio.

Reese, A.J., Cantrell, A. \& J. Scarborough, 1997: Sinkhole and drainage planning in Johnson City, Tennessee.In: Beck, B.F. \& B. Stephenson (eds.) Proceedings of the engineering geology and hydrogeology of karst terranes conference, $6^{\text {th }}-9^{\text {th }}$ April 1997, Springfield, Missouri. A.A. Balkema, 265-271, Brookfield, Vermont.

Rostamian, R., 2009: A funnel with variable inflow rate.[Online] Available from: http://www.math.umbc. edu/ rouben/2009-01-math481/proj1-rr.pdf [Accessed $21^{\text {st }}$ March 2009].

Schiesser, W.E., 1993: Computational Mathematics in Engineering and Applied Science: ODEs, DAEs, and PDEs.CRC Press LLC, pp. 587, Boca Raton, Florida.

Schoder, E.W. \& F.M. Dawson, 1934: Vorticity and Incompressible Flow.- McGraw-Hill Book Company, Inc., pp. 429, New York.

Sowers, G.F., 1996: Building on Sinkholes: Design and Construction of Foundations in Karst Terrain.American Society of Civil Engineers (ASCE) Publications, pp. 202, New York.

Streeter, V.L. \& E.B. Wylie, 1979: Fluid Mechanics.- McGraw-Hill Book Co., pp. 562, New York.

Sweeting, M.M., 1973: Karst Landforms.- Columbia University Press, pp. 362, New York. 
Waltham, T., Bell, F.G. \& M.G. Culshaw, 2005: Sinkholes and Subsidence: Karst and Cavernous Rocks in Engineering and Construction.- Springer, pp. 382, Chichester, U.K.

Waltham, T. \& Z. Lu, 2007: Natural and anthropogenic rock collapse over open caves.- In: Parise, M. \& J. Gunn (eds.) Natural and anthropogenic hazards in karst areas: Recognition, analysis, and mitigation. The Geological Society of London, pp. 13-21, London, U.K. [doi:10.1144/SP279.3]

Williams, P.W., 1971: Illustrating morphometric analyses of karst with examples from New Guinea.Zeitschrift für Geomorphologie, 15, 1, 40-61.
Williams, P.W., 1983: The role of the subcutaneous zone in karst hydrology.- Journal of Hydrology, 61, 4567.

Williams, P.W., 1985: Subcutaneous hydrology and the development of doline and cockpit karst.- Zeitschrift für Geomorphologie, 29, 463-482.

Zhou, W., 2007: Drainage and flooding in karst terranes.Environmental Geology, 51, 963-973. [doi:10.1007/ s00254-006-0365-3] 